\title{
High-speed trains and tourists: what is the link? Evidence from the French and Spanish capitals
}

\author{
F. Pagliara ${ }^{1}$, M. Delaplace ${ }^{2} \&$ J. M. Vassallo ${ }^{3}$ \\ ${ }^{1}$ Department of Civil, Architectural and Environmental Engineering, \\ 'Federico II' University of Naples, Italy \\ ${ }^{2}$ Lab'Urba IFU, Université Paris-Est, France \\ ${ }^{3}$ Departamento de Transportes, ETSI de Caminos, \\ Canales y Puertos, Spain
}

\begin{abstract}
The objective of this paper is to analyse the factors influencing tourists' choice of a destination and the role of High Speed Rail (HSR) systems in this choice. The methodology proposed consists in analysing two capitals in Europe, i.e. Paris and Madrid where HSR services are important, to investigate the factors influencing holidaymakers in choosing these cities, and the role of HSR in this choice.

The main outcome of this paper is to show that several factors influence the choice of a tourist, like the presence of architectural sites, the quality of promotion of the destination itself, the presence of events, and also HSR services. However we found that the HSR system has affected the choice of Paris and Madrid in a different way. Concerning the French case study, HSR is considered a real transport mode alternative among tourists, therefore HSR is chosen to reach Paris as well as for revisiting it. On the other hand, Madrid is chosen by tourists irrespective on the presence of HSR, while HSR is chosen for reaching cities close to Madrid. Data collected from the two surveys have been used for a further quantitative analysis. Models have been specified and calibrated to identify the factors influencing holidaymakers to revisit Paris and Madrid and the role of HSR in this choice has been highlighted.

Keywords: High Speed Rail, tourism market, regression models.
\end{abstract}




\section{Introduction}

Major investments on High Speed Rail (HSR) systems have been recently carried out all around the world. Asia is currently the leader in HSR systems in terms of $\mathrm{km}$ of lines with $13,732 \mathrm{~km}$ compared to $7,378 \mathrm{~km}$ in Europe. In the USA, HSR is nowadays being considered as an option. In 2010, the administration of President Obama budgeted $\$ 10$ billion for investment in HSR systems to connect major urban centres. However, most of the projects have been postponed for political and financial reasons.

HSR systems seem to represent the present and future of transport investments. The European Commission foresees that, by 2050, medium distance transport of passengers will take place by train including HSR [1] and many are the expected impacts.

This paper proposes an analysis of how tourism destination choice may be affected by HSR Services. Although there is a large literature on HSR services and tourism [2] the analysis on the link between HSR services and destination choice seems to have been investigated to a lesser extent.

However it is interesting to know the reasons why holidaymakers select and revisit their holiday destinations, and to investigate which factors are determining their choices. The objective of this paper is to investigate the role of HSR on the destination choice of tourists, and on the probability to return as tourists to the city where they were surveyed [3]. In the literature not many are the contributions, one of them is the paper by Seddighi and Theocharous [4]. It analyses the probability of revisiting Cyprus with respect to socio-demographic and destination characteristics. In this paper, a micro-econometric approach, based on observations of holidaymakers, is proposed. This approach allows the examination of the characteristics which influence individual travel behaviour and provides a conceptual and methodological framework for the understanding of the nature, form and character of the holiday-decision-making processes of individuals. Another paper analyses the different covariates of revisiting Lisbon by using a mixed logit model with bounded parameters. This researched found that the probability of revisiting Lisbon "increases significantly with accommodation range, events, food quality, expected weather, beach, overall quality, nightlife, reputation, and safety" [5].

However, currently and to our knowledge, there is no previous survey intending to evaluate the link between HSRS and 1) tourism destination choice and 2) tourism intention to return to an urban destination, apart from the case study of Rome [6], from which we learnt that tourists chose Rome independently on the presence of the HSRS but they choose it for visiting cities close to it.

This paper is organized as follows. In section 2 we analyse the results of the surveys conducted in Madrid and Paris. In section 3, on the basis of the results from the survey, we calibrate two models: first, the probability of revisiting Madrid and Paris and the impact of HSR on this choice; and second, the probability of visiting cities close to Madrid and Paris by HSR. Finally in section 4 , we show the conclusions of our research, and outline further perspectives. 


\section{The case studies}

The first HSR link in France, the South East HSR between Paris and Lyon, was opened in 1981 while in Spain the section Madrid-Cordoba-Seville $470 \mathrm{~km}$ long inaugurated in 1992 was the first one to be in operation. The two current HSR networks are reported in Figure 1.
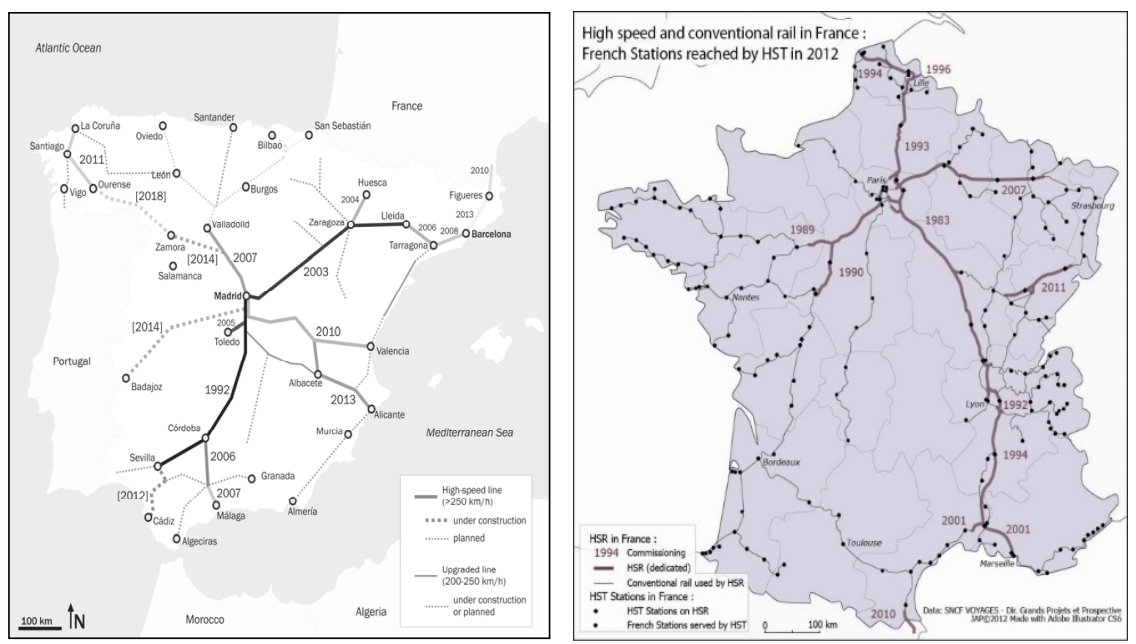

Source: Delaplace et al. (2014) [7].

Figure 1: The High Speed Rail systems in Spain (on the left) and in France (on the right).

Tourists visiting these two cities were surveyed randomly. In Paris, the survey was conducted from the 26th of October till the 2nd of November 2012 (from 7:45 a.m. till 7:00 p.m.) in three locations: the Eiffel Tower, Notre Dame Cathedral, and Paris Lyon Central Train Station, which had the greatest volume of HSR passengers (31.8 million passengers) in 2012.

In Madrid the survey was conducted from the 24th of June till the 28th of June 2013 (10.00 a.m. -2.00 p.m./4.00 p.m.-7.00 p.m.). The locations chosen were four famous tourist places: the Royal Palace, Mayor Square, Prado Museum, and Reina Sofia Museum.

The two questionnaires submitted are very similar in their content, but the number of questionnaires collected in Madrid (501) was higher than in Paris (226).

\subsection{The socioeconomic characteristics of the two case studies}

Five differences between the two surveys are worth to be mentioned. First, in Madrid the percentage of men in the sample was higher than in Paris. Second, the sample in Paris was more partnered than the one in Madrid. Third, the percentage of foreigners was greater in Madrid than in Paris (Delaplace et al. 
[7]). Fourth, in Madrid there were more employees and fewer managers than in Paris. And five, the income per capita was lower in Madrid than in Paris, which may be a consequence of the previous difference (see Table 1).

Table 1: Socioeconomic characteristics of the sample.

\begin{tabular}{|c|c|c|c|}
\hline \multirow{2}{*}{\multicolumn{2}{|c|}{ Number of complete interviews }} & \multirow{2}{*}{$\begin{array}{l}\text { Paris } \\
226\end{array}$} & \multirow{3}{*}{$\begin{array}{l}\text { Madrid } \\
501 \\
\end{array}$} \\
\hline & & & \\
\hline \multirow[t]{2}{*}{ Gender } & Female & $58 \%$ & \\
\hline & Male & $42 \%$ & $54.7 \%$ \\
\hline \multirow[t]{2}{*}{ Nationality } & French/Spanish & $42 \%$ & $27.7 \%$ \\
\hline & Foreigner & $58 \%$ & $72.3 \%$ \\
\hline \multirow[t]{3}{*}{ Age } & From ... to & $18-73$ & 18.79 \\
\hline & Mean & 38 & 39.5 \\
\hline & Most represented category & 25 to $44(43 \%)$ & 25 to $44(38 \%)$ \\
\hline \multirow[t]{2}{*}{ Family status } & Single & $32 \%$ & $46 \%$ \\
\hline & Partnered & $68 \%$ & $54 \%$ \\
\hline \multirow{3}{*}{ Travel } & In group & $76 \%$ & $84 \%$ \\
\hline & With family & $58 \%$ & Partner (30.5\%) \\
\hline & With friends & $19 \%$ & Relatives (27\%) \\
\hline \multirow[t]{3}{*}{ Degree } & University & $74 \%$ & $71 \%$ \\
\hline & High-school & $19 \%$ & $27 \%$ \\
\hline & Junior high-school & $7 \%$ & $2 \%$ \\
\hline \multirow[t]{3}{*}{ Occupation } & Employee & $33 \%$ & $45.5 \%$ \\
\hline & Manager ir executives & $23 \%$ & $6 \%$ \\
\hline & Student & $19 \%$ & $18 \%$ \\
\hline \multirow{3}{*}{$\begin{array}{l}\begin{array}{l}\text { Income } \\
\text { month }\end{array} \\
\end{array}$} & Between $2500 €$ and $4500 €$ & $55 \%$ & $32 \%$ \\
\hline & More than $4500 €$ & $22 \%$ & $10 \%$ \\
\hline & Lower than $500 €$ & $10 \%$ & $29 \%$ \\
\hline
\end{tabular}

\subsection{Transport modes to reach the two cities}

Concerning the transport modes used by tourists to get to the two cities, the most notable difference is that HSR is used most in Paris than in Madrid.

In Madrid, the modes most frequently used by the surveyed tourists to get to the city were the airplane (59.1\%), HSR (12.8\%), and car (11\%). A lower percentage chose the coach, other long-distance rail, and intercity rail $(9 \%, 4 \%$ and $4 \%$ respectively). For obvious reasons, the airplane is used mostly by foreigners. Only $8.6 \%$ of the Spanish tourists chose the plane to get to Madrid, $28 \%$ arrived in Madrid by HSR, $28 \%$ by car, and $18 \%$ by coach. Foreign tourists arrived mostly by plane (78.5\%) due to their constraints to choose another mode of transport. Only $6.9 \%$ of them arrived in the city by HSR.

In the Parisian case, $49 \%$ came by HSR (38\% of foreigners respondents and $64 \%$ for French ones), 34\% by plane, with higher rates for foreign tourists $(52 \%$ of foreign respondents, but only $8 \%$ of French ones), and $15 \%$ by car ( $10 \%$ for foreigners ones). 
The total duration of the trip (including departure from home, arrival in the city, travel to other cities, overnight and return home) is also different. It was on average 14 days in Madrid, but only 7 days in Paris. However, the average duration of the stay is the same in the two cities (5 days).

The average budget of the tourists visiting Madrid was €2 150 for the whole trip, and $€ 1050$ in Paris (from less than $€ 50$ to $€ 12,000$ ).

Concerning the influence of HSR, the results are very similar, except for the accessibility to the stations. $41 \%$ of respondents in Madrid were positively influenced by the presence of HSR in their destination choice, especially because of the speed (66\%), the possibility to visit other cities linked by HSR (13\%), and the accessibility of the departure/arrival station (7\%). $49 \%$ of respondents in Paris were positively influenced by the presence of HSR in the destination choice, especially because of the speed of the travel (94\%), and also for the good accessibility of both departure (75\%) and destination stations (72\%). Frequency of the service $(56 \%)$ and the decreasing of the travel time in case of new services $(51 \%)$ were also important motivations.

\subsection{The motivations to visit and revisit the two cities}

Concerning the main motivation to visit the cities, in the case of Paris, HSR was the third main motivation after cultural offers (83\%) and historical and architectural landmarks (81\%). Gastronomy (47\%), presence of relatives in the Parisian area $(46 \%)$ or personal events $(42 \%)$ were also important motivations for visiting Paris, but they were not as important as the presence of HSR. 75\% of the respondents influenced by HSR services actually used HSR to get to Paris. The cost of the ticket supports that choice $(36 \%)$, and the duration of the travel (34\%) were almost equally important. The convenience $(23 \%)$, due to the level of services, and the existence of the service (a possible HSR offer) (19\%) had a strong influence for not choosing HSR.

The historical and architectural landmarks are the main motivations influencing the tourist to choose Madrid as a tourist destination (40.1\%) followed by presence of relatives/friends in the area of Madrid (26.3\%), and cultural offers and gastronomy (15.8\%). Shopping and general events (sport, music, etc.) (12.4\%) were also important motivations for visiting Madrid, HSR is the last motivation with only $0.8 \%$. The Spanish tourists are not sensitive to HSR services in the choice of that destination (only 1\%). $65.5 \%$ of the respondents influenced by HSR services arrived by HSR. Almost all the sample does not considered HSR a motivation for choosing Madrid as a tourist destination. Actually, $87 \%$ of respondents have not used HSR to come to Madrid. This choice has been made because $64 \%$ of the tourist were not able to get to Madrid by HSR, the high cost of the ticket (17.5\%), the accessibility of the departure/arrival station $(8 \%)$, and travel time $(9 \%)$ which are quite important factors for this choice. The tourists in Madrid seem to be more sensitive to the price than the ones in Paris.

Concerning the revisiting of the two capitals, the results are quite similar. $78 \%$ of the respondents were willing to revisit Madrid for another holiday, but 
they were mostly foreigners arriving by plane. For the case of Paris, both French $(99 \%)$ and foreign tourists $(97 \%)$ wished to come back.

Those who intended to return to Madrid were driven by the richness of the historical, artistic, monumental heritage and cultural events (48\%). On the other hand, tourists that have already visited all the attractions in Madrid (43\%), and those whose home country is far away (37.3\%) are not willing to return. Concerning the case study of Paris, the motivations of the respondents who wish to revisit this destination were mostly linked to their wish to discover more in the city $(40 \%)$, and the attractiveness of the destination $(36 \%)$. The presence of relatives was a strong motivation (27\%), more important than tourist supply $(20 \%)$. This percentage was high, irrespective of the transport mode used to reach Paris.

\subsection{Impact of HSR on tourists visiting other cities connected through this service}

The results of the survey conducted in Madrid show at first sight that the presence of the HSR does not have a clear influence on tourists' choices of visiting other cities near Madrid. However there were a lot of respondents $(62.1 \%)$ who actually visited another places, and $56 \%$ of them used HSR with that purpose. $90 \%$ of respondents visiting other destinations were foreigners, and $52 \%$ of them used the HSR to reach these destinations. The tourists who used the HSR

to

visit

other locations in the country did it because of travel time savings $(73.6 \%)$. On the other hand the main motivation for not using HSR to visit other cities near Madrid was the high cost of the ticket (34\%), and the lack of connection between Madrid and the chosen destination (51\%).

In the case of Paris, $20 \%$ of the respondents were visiting another place during their trip. $43 \%$ of them were influenced by the HSR services for choosing to visit others places, and 53\% were actually using it. In several cases, they were not able to reach it by HSR (too far, no offers etc.). For those respondents visiting other destinations, $61 \%$ were foreign tourists but they were less sensitive than French tourists to HSR services.

\section{Modelling the probability of revisiting Paris and Madrid and visiting cities close to them by HSR}

\subsection{The probability to revisit Paris and Madrid: very different results}

A further quantitative analysis has been carried out. Regression models have been specified and calibrated to identify the factors influencing holidaymakers to revisit Madrid and Paris.

The literature on logistic regression is large and has been growing since 1970, especially in social sciences and educational research. These models have been extensively applied also for the analysis of tourist demand (Witt and Witt [9]), especially to explain the decision to do/not to do a holiday. In both case studies, 
the probability of revisiting the city has been specified according to a very simple linear regression model. We are aware that the approach is fairly straightforward, since user choices are mostly affected by non-linearity and uncertainty which have not been considered in this paper. In spite of that, it seems interesting to provide a preliminary quantitative insight on the basis of the data from the two surveys conducted.

The variables we chose to calibrate the model are the following:

AGE_18-24

MARRIED

FREELANCE

NATION

UNIV

FIRST_TIME_CITY

STAY_RELAT_HOME

TRAV FRIENDS

HSR dummy variable equal to 1 if the tourist's age is between 18-24; 0 otherwise.

dummy variable equal to 1 if the tourist is married; 0 otherwise.

dummy variable equal to 1 if the tourist is a freelance; 0 otherwise.

dummy variable equal to 1 if the tourist is French/Spanish; 0 otherwise.

dummy variable equal to 1 if the tourist attended the university; 0 otherwise.

dummy variable equal to 1 if the tourist has never been before in the City; 0 otherwise.

dummy variable equal to 1 if the tourist stays at his/her relatives' home; 0 otherwise.

dummy variable equal to 1 if the tourist travel with friends; 0 otherwise.

dummy variable equal to 1 if the tourist was influenced by the presence of HSR; 0 otherwise.

TRANSP COST $>700 €$ dummy variable equal to 1 if the tourist has spent more than $700 €$ for transport; 0 otherwise.

VISIT_RELAT dummy variable equal to 1 if the tourist visit relatives at destination; 0 otherwise.

ARCHITECT dummy variable equal to 1 if the tourist is attracted by the architectural sites at destination; 0 otherwise.

MULTI_DEST dummy variable equal to 1 if the tourist can visit also from the chosen destination another city; 0otherwise.

EVENT dummy variable equal to 1 if the tourist is attracted by events at destination; 0 otherwise.

The type of tourists that most likely will revisit Madrid and Paris will be analyzed, given their socio-economic, tourist and transport related attributes. The dependent variable is the willingness to revisit Madrid or Paris (Yes: 1, No: 0), the independent variables are the attributes above listed. Estimation results are reported in Table 2 . In the case of Madrid, the model presents a high explanatory power indicating that the model fits the sample data pretty well. All the parameters are highly significant (except TRANSP_COST $>700 €$ and the HSR variable, which are not significant) even though they have the expected sign. 
Indeed, the satisfaction of past experience (FIRST_TIME_MADRID) has a positive impact on the probability to revisit Madrid. In fact those people who already visited Madrid have a higher chance of returning. With reference to the socio-economic characteristics, the Spaniards have a higher probability to revisit Madrid.

Transport characteristics seem not to have a big impact on the destination choice. Indeed, although the transportation cost has the correct sign, it is not significant, which means that it is not an attribute relevant to determine destination choice [8]. Nevertheless, the quality of promotion of heritage resources is important. The main outcome from the Madrid case study is that tourists will revisit the city irrespective on the presence of the HSR.

In the case of Paris, all the attributes are significant and have the expected sign. Tourists that are willing to revisit Paris are younger than the average. They are French, aged between 18 and 24, and were at the university when they were surveyed. They travel with friends, and they would like to go back to Paris because of its architectural sites, the opportunity of visiting other places from there, and the possibility of visiting relatives. Paris is also a city full of events, and this is a factor influencing the choice to come back, particularly for the youth. The HSR variable is very significant and positive, meaning that for the young people the presence of HSR influences their choice. The variable itself embeds all the characteristics connected with HSRS, i.e. high speed, reduction of travel times, high frequency, reliability, easy access to the station, and so on. Moreover young people know that reduced fares are available so they can benefit from this fact to come back.

Table 2: $\quad$ Variables influencing the probability of revisiting Madrid and Paris.

\begin{tabular}{|l|c|c|}
\hline \multirow{2}{*}{ Variable } & Madrid & Paris \\
\cline { 2 - 3 } & Coefficient (t-test) & Coefficient (t-test) \\
\hline AGE_18-24 & - & $0.105(1.979)$ \\
\hline MARRIED & $-0.063(-2.315)$ & - \\
\hline FREELANCE & $0.104(2.2040)$ & - \\
\hline NATION & $0.121(3.633)$ & $0.192(3.904)$ \\
\hline UNIV & - & $0.238(5.111)$ \\
\hline FIRST_TIME_MADRID & $-0.083(-2.809)$ & - \\
\hline STAY_RELAT_HOME & $0.111(2.131)$ & - \\
\hline TRAV_FRIENDS & - & $0.167(3.063)$ \\
\hline HSR & $-0.015(-0.552)^{*}$ & $0.177(4.167)$ \\
\hline TRANSP_COST>700€ & $-0.028(-0.954)^{*}$ & - \\
\hline VISIT_RELAT & - & $0.160(3.416)$ \\
\hline ARCHITECT & $-0.559(20.409)$ & $0.434(9.712)$ \\
\hline MULTI_DEST & - & $0.172(3.677)$ \\
\hline EVENT & - & $0.0902(2.036)$ \\
\hline Rho2 & 0.493 & 0.650 \\
\hline Rho ${ }^{2}$ adj & 0.485 & 0.595 \\
\hline
\end{tabular}

*Not significant. 


\subsection{Modelling the probability of visiting cities close to Paris and Madrid by HSR}

The second model intends to identify which variables have an impact on the use of HSR to travel from Madrid or Paris towards nearest cities served by HSR. The variables are in the following described and the estimation results are reported in Table 3.

INCOME_0-2500Euro dummy variable equal to 1 if the tourist's income is between is less than 2500 Euro per month; 0 otherwise.

TOT_HOLID_7days_dummy variable equal to 1 if the tourist's total holiday is less than 7 days; 0 otherwise.

STAY_CITY_5days dummy variable equal to 1 if the tourist's stay in Paris is less than 5 days; 0 otherwise.

TOT_HOLID_COST dummy variable equal to 1 if the tourist's total holiday cost is less than 1000 Euros; 0 otherwise.

EASY_2NEARCITIES dummy variable equal to 1 if the easy access to cities located nearby to the city where the survey was conducted has influenced the choice of the tourist for HSR; 0 otherwise.

SAFETY

SERV_FREQ

dummy variable equal to 1 if for the tourist, safety has influenced the choice of HSR; 0 otherwise.

dummy variable equal to 1 if for the tourist, service frequency has influenced the choice of HSR; 0 otherwise.

TICKET_COST dummy variable equal to 1 if for the tourist, ticket cost has influenced the choice of HSR; 0 otherwise.

COMFORT

STATION_ACCESS dummy variable equal to 1 if for the tourist, comfort has influenced the choice of HSR; 0 otherwise.

The dependent variable of this model is the importance of the HSR presence to promote that tourists visit nearby cities connected by HSR (Important: 1, Not important: 0 ). The independent variables are socio-demographic and transport attributes.

In the case of Madrid, all the attributes have the expected sign and are significant: the probability to reach nearby cities by AVE (EASY_2NEARCITIES), the accessibility of departure/arrival station (STATION_ACCESS), travel comfort (COMFORT), service frequency (SERV_FREQ), and safety (SAFETY) have a positive impact on the probability to use $\overline{H S R}$ service to visit cities located nearby. The cost of transportation (TICKET_COST) has a negative impact. Foreign tourists are using HSR more frequently than national ones to move to cities close to Madrid by HSR. This fact is confirmed by the negative sign of the variable NATION. 
In the case of Paris, the average tourists that will likely visit cities close to Paris by HSR are French with income below $€ 2500$ a month, and are going to stay in Paris less than 5 days out of a trip 7 days long. They will choose TGV because of the easy access to two nearby cities connected by it, and their total cost for the holiday is less than 1000 Euros.

Consequently the role of HSR in the probability of visiting other cities is different in Madrid compared to Paris. In Madrid this is for foreigners while in Paris this is for French people.

Table 3: Variables influencing the probability of visiting cities close to Madrid and Paris by HSR.

\begin{tabular}{|l|c|c|}
\hline \multirow{2}{*}{ Variable } & Madrid & Paris \\
\cline { 2 - 3 } & Coefficient (t-test) & Coefficient (t-test) \\
\hline NATION & $-0.140(-2.249)$ & $0.108(2.417)$ \\
\hline INCOME_0-2500Euro & - & $0.084(1.954)$ \\
\hline TOT_HOLID_7days & - & $-0.425(-7.443)$ \\
\hline STAY_CITY_5days & - & $0.238(4.589)$ \\
\hline TOT_HOLID_COST & - & $-0.257(-2.792)$ \\
\hline EASY_2NEARCITIES & $0.296(5.101)$ & $0.289(5.822)$ \\
\hline SAFETY & $0.273(4.547)$ & - \\
\hline SERV_FREQ & $0.328(4.317)$ & - \\
\hline TICKET_COST & $-0.359(-6.921)$ & - \\
\hline COMFORT & $0.456(10.658)$ & - \\
\hline STATION_ACCESS & $0.398(7.419)$ & - \\
\hline$\rho 2$ & 0.631 & 0.41 \\
\hline$\rho^{2}$ adj & 0.594 & 0.392 \\
\hline
\end{tabular}

\section{Conclusions and further perspectives}

The objective of this paper has been that of investigating the factors influencing destination choice for tourism purposes in order to identify the role of HSR systems in determining this choice. Even though several factors influence the choice of a tourist, like the presence of architectural sites, the quality of promotion of the destination itself, the presence of events, etc., HSR systems also play a role in the choice of tourists, but in a different way in the two case studies. HSR is considered in France a real alternative transport mode for tourists. As the results of the models show, tourists in France choose it for moving around the country for their holiday. On the other hand, HSR services are not so crucial for tourists visiting Madrid since they will be willing to revisiting the city independently on the presence of HSR as it happened in the case of Rome (Valeri et al. [6]). However, HSR are important for foreign tourists visiting Madrid as a means of visiting tourist spots nearby the city.

Further investigation is necessary to understand the specific role of HSR system on tourism in other countries and, inside the same countries, in other cities and especially intermediate cities linked by HSRS to the capital. Findings provide useful information for analysts in their efforts to segment and target 
specific tourist segments and to public actors of these intermediate cities to pay for or not HSRS. A greater awareness of tourists' characteristics with respect to a specific destination represents an important input for improving packaging and promotion. HSR operators, for instance, could develop specific HSR discount tickets when travelling for tourism purposes as in the case of China.

The results obtained, even if preliminary and based on a limited number of interviews, suggest the implementation of more sophisticated and wide ranging surveys taking into consideration other relevant and transport related dimensions at a regional, national and international level as well.

\section{Acknowledgements}

The authors would like to thank Julie Perrin and Samuel Mermet for collecting data for the Paris case study and the first descriptive statistical analysis; and Andrea La Pietra, and Juan Gómez for collecting data for the Madrid case study.

\section{References}

[1] EC, White Paper, Roadmap to a Single European Transport Area - Towards a competitive and resource efficient transport system, 2011.

[2] Bazin, S., Beckerich, C., Blanquart, C., Delaplace, M. \& Vandebossche L. Grande vitesse ferroviaire et développement économique local: une revue de la littérature. Recherche, Transports et Sécurité, 27-106, pp. 215-238, 2011.

[3] Biggiero, L., The impact of transport management on local activities system: The role of limited traffic zones. WIT Transactions on the Built Environment, 138, 2014.

[4] Seddighi, H.R. \& Theocharous, A.L., A model of tourism destination choice: a theoretical and empirical analysis. Tourism Management, 23, pp. 475-487, 2002.

[5] Barros, C. P. \& Assaf A. G., Analyzing Tourism Return Intention to an Urban Destination. Journal of Hospitality \& Tourism Research, 36, pp. 216-231, 2012.

[6] Valeri, E., Pagliara, F. \& Marcucci, E. A destination choice model for tourism purpose. ASRDLF 2012 conference special session on High Speed Rail, Tourism and Territories, $9^{\text {th }}-11^{\text {th }}$ July, Belfort, France, 2012.

[7] Delaplace, M., Pagliara, F., Perrin, J. \& Mermet. S., Can High Speed Rail foster the choice of destination for tourism purpose? Procedia - Social and Behavioral Sciences, forthcoming, 2014.

[8] D’Acierno, L., Gallo, M., Biggiero, L. \& Montella, B., The replanning of public transport services in the case of budget reductions. WIT Transactions on the Built Environment, 138, 2014.

[9] Witt, S.F. \& Witt, C.A. (1995), 'Forecasting tourism demand: a review of empirical research', International Journal of Forecasting, Vol 11, pp. 447475. 